University of New Hampshire

University of New Hampshire Scholars' Repository

Earth Systems Research Center

Institute for the Study of Earth, Oceans, and

Space (EOS)

$1-16-2017$

\title{
Major fraction of black carbon is flushed from the melting New Hampshire snowpack nearly as quickly as soluble impurities
}

James Lazarcik

University of New Hampshire, Durham

Jack E. Dibb

University of New Hampshire, Durham, jack.dibb@unh.edu

Alden C. Adolph

Dartmouth College

Jacqueline M. Amante

University of New Hampshire, Durham

Cameron P. Wake

University of New Hampshire, Durham, cameron.wake@unh.edu

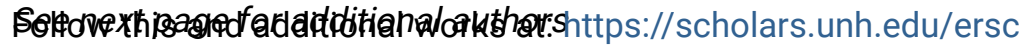

Comments

This is an article published by AGU in Journal of Geophysical Research: Atmospheres in 2017, available online:

https://dx.doi.org/10.1002/2016JD025351

\section{Recommended Citation}

Lazarcik, J., J. E. Dibb, A. C. Adolph, J. M. Amante, C. P. Wake, E. Scheuer, M. M. Mineau, and M. R. Albert (2016) Major fraction of black carbon is flushed from the melting New Hampshire snowpack nearly as quickly as soluble impurities, Journal of Geophysical Research, 121, 537-553, https://dx.doi.org/10.1002/ 2016JD025351

This Article is brought to you for free and open access by the Institute for the Study of Earth, Oceans, and Space (EOS) at University of New Hampshire Scholars' Repository. It has been accepted for inclusion in Earth Systems Research Center by an authorized administrator of University of New Hampshire Scholars' Repository. For more information, please contact Scholarly.Communication@unh.edu. 


\section{Authors}

James Lazarcik, Jack E. Dibb, Alden C. Adolph, Jacqueline M. Amante, Cameron P. Wake, Eric M. Scheuer, Madeleine M. Mineau, and Mary R. Albert 


\section{Journal of Geophysical Research: Atmospheres}

\section{RESEARCH ARTICLE \\ 10.1002/2016JD025351 \\ This article is a companion to Adolph et \\ Major fraction of black carbon is flushed from the melting New Hampshire snowpack nearly as quickly as soluble impurities} al. [2016] doi:10.1002/2016JD025362.

Key Points:

- Seasonal snowpacks store major ions and $\mathrm{BC}$ throughout the winter and release them quickly in high concentrations at the onset of melt

- Up to $60 \%$ of total snowpack BC is washed from the snowpack in the first $24 \%$ of snow-water equivalence loss - Late season enhancement of surface BC concentrations could not be linked to melt events in this study

Correspondence to:

J. Lazarcik,

j12022@wildcats.unh.edu

\section{Citation:}

Lazarcik, J., J. E. Dibb, A. C. Adolph, J. M. Amante, C. P. Wake, E. Scheuer, M. M. Mineau, and M. R. Albert (2017), Major fraction of black carbon is flushed from the melting New Hampshire snowpack nearly as quickly as soluble impurities, J. Geophys. Res. Atmos., 122, 537-553, doi:10.1002/2016JD025351.

Received 13 MAY 2016 Accepted 1 DEC 2016 Accepted article online 6 DEC 2016 Published online 9 JAN 2017

\author{
James Lazarcik ${ }^{1,2}\left(\mathbb{D}\right.$, Jack E. Dibb ${ }^{1,2}$ (D) Alden C. Adolph ${ }^{3}$ (D) Jacqueline M. Amante ${ }^{1,2}$, \\ Cameron P. Wake, ${ }^{1,2}$, Eric Scheuer ${ }^{2}$, Madeleine M. Mineau ${ }^{2}$ (D) and Mary R. Albert ${ }^{3}$ \\ ${ }^{1}$ Department of Earth Science, University of New Hampshire, Durham, New Hampshire, USA, ${ }^{2}$ Institute for the Study of \\ Earth, Oceans, and Space, University of New Hampshire, Durham, New Hampshire, USA, ${ }^{3}$ Thayer School of Engineering, \\ Dartmouth College, Hanover, New Hampshire, USA
}

Abstract Seasonal snowpacks accumulate impurities derived from atmospheric aerosols and trace gases throughout the winter and release them during snowmelt. Previous field and laboratory studies have shown that a snowpack can lose up to $80 \%$ of the soluble ion burden in the first $20 \%$ of the melt, an event commonly known as an ionic pulse. Other studies have concluded that particulate impurities (e.g., black carbon (BC)) concentrate in surface layers during melt which can have important implications for snowpack albedo. However, model and field studies have indicated that meltwater scavenging efficiency of BC in melting snowpacks is still an area of uncertainty. To quantify BC melt dynamics and the release of soluble impurities, we collected and analyzed near-daily chemical profiles in the snowpack at three sites during two winters in New Hampshire, United States of America. We observe an ionic pulse and a pulse of BC from the snowpack at the onset of melt; up to $62 \%$ of BC leaves within the first $24 \%$ of the melt. Surface concentrations of $\mathrm{BC}$ are higher than seasonal medians at the end of the winter season, but surface enhancements do not appear to be closely linked to decreases in snow-water equivalence caused by melting.

\section{Introduction}

Black carbon (BC) may be one of the most important individual contributors to climate warming [Hansen and Nazarenko, 2004; Bond et al., 2013]. Recent estimates for total radiative forcing by BC are as high as $+0.40 \mathrm{~W} /$ $\mathrm{m}^{2}(+0.05$ to +0.80$)$ [Myhre et al., 2013]. The presence of BC in and on snow and ice contributes approximately $10 \%\left(+0.04 \mathrm{~W} / \mathrm{m}^{2}(+0.02\right.$ to +0.09$\left.)\right)$ of the total radiative forcing effect due to its high absorption of visible light [Bond et al., 2013; Myhre et al., 2013]. When BC is on the surface snow, it has potential to darken the snowpack and lead to a positive albedo and grain size growth feedback loop. The effect of this feedback loop is increased absorption of solar radiation causing acceleration of snowmelt and grain growth, further decreasing snow albedo thereby decreasing snow cover duration and global surface albedo [Flanner et al., 2007; Doherty et al., 2013]. Thus, the behavior of BC in arctic, subarctic, and high-altitude snowpacks is an active area of research [Doherty et al., 2010; Doherty et al., 2013; Bond et al., 2013; Doherty et al., 2016]. There is little published field data regarding the behavior of BC in midlatitude, low-altitude seasonal snowpacks during melt, though Doherty et al. [2014, 2016] extensively discuss midlatitude BC in central North America and the mountains of Idaho and Utah, respectively. Furthermore, Doherty et al. [2016] offer analysis of BC in the snowpack surface during periods of warm temperatures.

Recent studies in melting snowpacks have found that BC amplifies on the surface [Xu et al., 2012; Meinander et al., 2013; Doherty et al., 2013; Doherty et al., 2016], where a reduction of snowpack albedo due to elevated BC concentrations could be significant [Flanner et al., 2007]. Other studies have shown a flushing of particles during melt [Conway et al., 1996], sometimes causing a 75\% reduction in integrated BC concentration [Sterle et al., 2013]. Studies that focus on melt accumulation or deposition of BC [Hansen and Nazarenko, 2004; Aamaas et al., 2011; Svensson et al., 2013; Tedesco et al., 2016] often cite Conway et al. [1996] in support of a melt accumulation or enhancement argument, though Conway et al. showed that even most hydrophobic soot still flushed through the snowpack with high efficiency. Large BC meltwater scavenging efficiencies have the potential to significantly decrease the radiative forcing effect of BC in snow [Qian et al., 2014].

This study uses daily snowpit measurements to focus on changes in BC burden and distribution during active melt in New Hampshire's (NH) seasonal snowpack. We also include measurements of major ions $\mathrm{Cl}^{-}$and 
$\mathrm{NO}_{3}{ }^{-}$to validate our approach of evaluating changes in impurity burden. Previous studies using lysimeters have shown that ionic species pulse from the snowpack at the onset of melt [Johannessen et al., 1976; Johannessen and Henriksen, 1978; Hibberd, 1984; Williams and Melack, 1991; Bales et al., 1989; Harrington and Bales, 1998a, 1998b; Satoh et al., 1999; Feng et al., 2001; Lee et al., 2008; Williams et al., 2009]. Therefore, if daily integrated snowpit sampling allows us to detect a pulse of major ions, the same method should be applicable to the study of BC melt dynamics. Since meltwater scavenging efficiency for BC is much lower than for major ions [Colbeck, 1981; Doherty et al., 2013], we expect natural contrast between major ion and BC melt dynamics.

The initial motivation for this study was to investigate the effects of $\mathrm{BC}$ evolution in the melting $\mathrm{NH}$ seasonal snowpack on albedo. An in-depth analysis regarding BC, optical grain size, and albedo in the seasonal $\mathrm{NH}$ snowpack is provided in Adolph et al. [2016]. Adolph et al. [2016] find that the albedo effect of BC in NH snow is secondary to grain size effects. However, observations of $B C$ in melting snowpacks presented in this work may help reduce model or module uncertainty associated with treatment of BC in aging snow [Flanner et al., 2007].

\section{Methods}

\subsection{Site Locations}

Physical and chemical snowpack properties were measured at three sites spanning the southern half of New Hampshire (Figure 1). Two sites were located near the University of New Hampshire, Durham, $\mathrm{NH}$, in $\mathrm{New}$ Hampshire's seacoast region, Burley-Demeritt Open Field (BDO, N 4305', W 70 59', $35 \mathrm{~m}$ above sea level

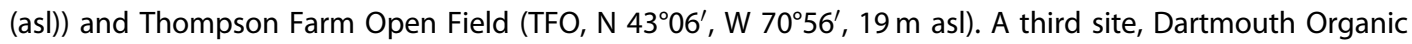
Farm Open Field (DFO, N 434ㄴ ${ }^{\prime}, \mathrm{W} 72^{\circ} 15^{\prime}, 119 \mathrm{~m}$ asl) was located on the border of New Hampshire and Vermont along the Connecticut River near Dartmouth College in Hanover, NH. The Hanover site was located

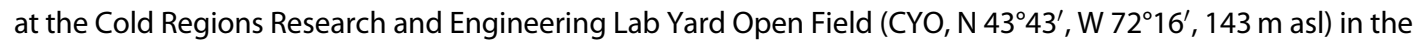
winter of 2013-2014. The site was moved to a nearby farm in the winter of 2014-2015 to be more similar to the open farm field sites established near the seacoast. Each field site consists of gently sloping or level terrain and is near meteorological stations, which collect relevant meteorological data throughout the winter.

\subsection{Sampling Summary}

Two sampling seasons are studied in this work, referred to as Winter 2 and Winter 3 (Table 1). A first winter (Winter 1) was a trial sampling season. Data for Winter 1 can be found at https://ddc.unh.edu/ddc_data/variables/list/. Sampling seasons vary in collection days and sampling frequency (Table 1); the target was to sample the snowpack daily. Winter 2 was a warmer winter season overall [Adolph et al., 2016], but CYO saw its highest snowfall totals as well as its highest percentage of coastal/sea-based storms [Adolph et al., 2016]. Winter 3 (the most complete sampling campaign) was a colder winter at all three sites. BDO/TFO saw its highest snowfall totals, and DFO received its highest percentage of land-based storms. Adolph et al. provide more details pertaining to winter campaign meteorological trends and differences.

\subsection{Snowpit Sampling}

Field sampling involved multiple measurements in an area of previously undisturbed snow. A snowpit was dug and a planar wall created using a plastic shovel that was carefully cleaned daily with $18 \mathrm{M} \Omega$ reverse osmosis water. Then, depth range and temperature in each identifiable snowpack layer were determined. Depth was characterized with a ruler. Albedo and grain size were also characterized, and Adolph et al. [2016] provide information regarding albedo and grain size sampling and analysis.

In Winter 3, snow samples of known volume and depth were collected at ambient temperature continuously from top to bottom discretely by visible snowpack layers. In Winter 2, samples were obtained in fixed depth increments regardless of snowpack layers. Samples were excavated using a carefully cleaned stainless steel $100 \mathrm{~mL}$ density cutter. In the field, samples were put in tared, precleaned $175 \mathrm{~mL}$ high density polyethylene (HDPE) bottles [Dibb et al., 2007]. Two side-by-side scoops at a depth resolution of 1 to $6 \mathrm{~cm}$ were placed into a single bottle. After collection, samples were stored in a cooler with sufficient thermal mass for transport back to the lab where they were weighed to determine sample density and snow-water equivalence (SWE). Samples were subsequently stored in a freezer at approximately $-20^{\circ} \mathrm{C}$ until analysis. 


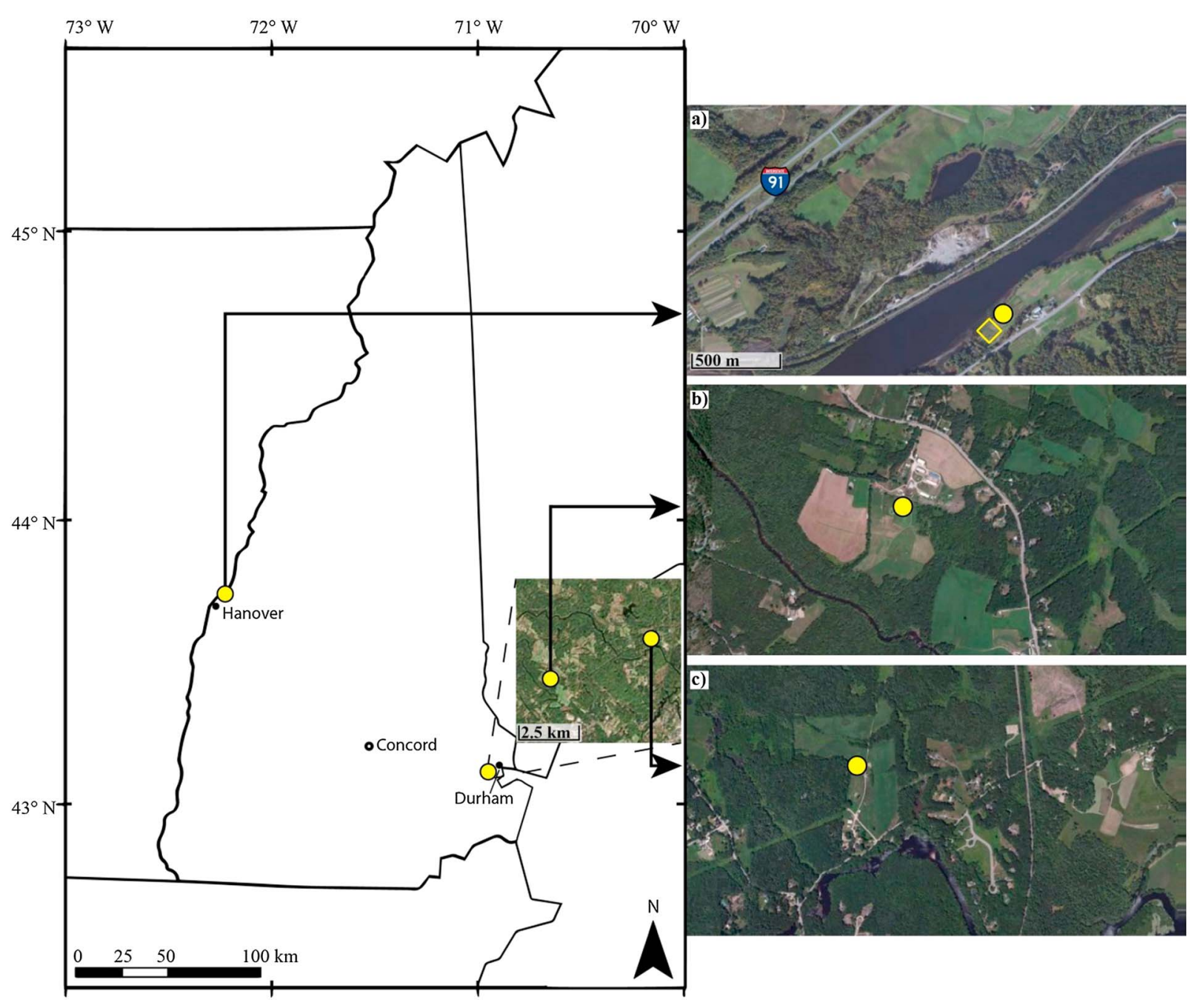

Figure 1. Site locations for Winter 3. (a) DFO on the western edge of New Hampshire in Hanover is near I-91 on the Connecticut River. (b) BDO and (c) TFO on the seacoast are located in Lee, $\mathrm{NH}$, and Durham, $\mathrm{NH}$, respectively. The yellow square in Figure $1 \mathrm{a}$ is the approximate location of three separate surveys where samples were taken for spatial variability analysis.

After a daily pit had been excavated and sampled, it was refilled using the original snow. This helps mitigate the development of horizontal temperature gradients and stop flux of water vapor and atmospheric aerosols into and out of the full depth of the snowpack. Subsequent pits were typically located in an area of undisturbed snow $0.5 \mathrm{~m}$ southeast of the previous pit. Because each daily pit is in a slightly

Table 1. Overview of Sampling Seasons

\begin{tabular}{lccc} 
Site & Sampling Window & Fraction of Days Sampled in Window ${ }^{\mathrm{a}}$ & Total Number of Samples $^{c}$ \\
\hline & & Winter 3: 2015 & \\
DFO & 1 Jan to $4 \mathrm{Apr}$ & $81 / 93$ & 604 \\
BDO & 9 Jan to 4 Apr & $77 / 85$ & 555 \\
TFO & 9 Jan to 4 Apr & $76 / 85$ & \\
& & Winter 2: 2013-2014 & 491 \\
CYO & & $76 / 113$ & 312 \\
BDO & 18 Dec to 10 Apr & $62 / 92$ & 390 \\
TFO & 18 Dec to 20 Mar & $73 / 101$ & \\
\hline
\end{tabular}

${ }^{a}$ Number of sampled snowpits over possible number of pits.

${ }^{\mathrm{b}} \mathrm{CYO}$ moved northeast to a nearby field (DFO) in Winter 3.

${ }^{c}$ Number of samples analyzed for major ions and BC. 
different location, meter scale spatial variability of impurities and SWE were also characterized through seven spatial surveys.

\subsection{Analysis}

Snow samples were melted in batches of five by standing the sample bottle in a room temperature water bath prior to analysis. Immediately after melting, each sample was sonicated for at least $15 \mathrm{~min}$ then aliquoted to a smaller analysis bottle. First, snow water was analyzed for BC concentration via laser-induced incandescence on the single-particle soot photometer (SP2; Droplet Measurement Technologies). Liquid snow samples were aerosolized with an ultrasonic nebulizer (USN) (CETAC U5000AT) at a constant 1 standard liters per minute air flow and $0.6 \mathrm{~mL} / \mathrm{min}$ liquid sample introduction. The SP2 and nebulizer were both externally calibrated with fullerene soot [Schwarz et al., 2006]. After analysis on the SP2, samples are queued for major ion analysis $\left(\mathrm{Na}^{+}, \mathrm{NH}_{4}^{+}, \mathrm{K}^{+}, \mathrm{Mg}^{2+}, \mathrm{Ca}^{2+}, \mathrm{Cl}^{-}, \mathrm{NO}_{3}{ }^{-}\right.$, and $\mathrm{SO}_{4}{ }^{2-}$ ) via ion chromatography (IC) [Dibb et al., 2007], though $\mathrm{Cl}^{-}$and $\mathrm{NO}_{3}{ }^{-}$are the primary major ion focus in this work.

Analysis of BC can be complicated by a variety of factors, one of which is diameter-dependent nebulizer efficiency. The U5000AT has decreased efficiency for particles $>500 \mathrm{~nm}$ [Schwarz et al., 2012; Ohata et al., 2013; Wendl et al., 2014] and has been specifically advised against for snow analysis where particle diameters are expected to be greater than $500 \mathrm{~nm}$ [Schwarz et al., 2012]. Based on preliminary SP2 results from this study, BC mass concentration diameter modes should be within the most efficient range of the U5000AT, or about $100 \mathrm{~nm}$ to $500 \mathrm{~nm}$ [Ohata et al., 2013], and similar to fullerene soot standard diameters [Laborde et al., 2012; Wendl et al., 2014].

Dust may externally mix with BC and increase particle size. The SP2 is relatively insensitive to external dust/BC mixtures [Schwarz et al., 2012; Wendl et al., 2014], but the U5000AT may inefficiently aerosolize particle mixtures with a diameter of $>500 \mathrm{~nm}$. The presence of dust may cause a low bias in BC measurements if dust is ubiquitous in $\mathrm{NH}$ snow samples, though $\mathrm{BC}$ is not typically mixed with large amounts of non-BC matter in a single particle [Schwarz et al., 2012]. A recent study concluded that even midlatitude North American sites far from globally significant dust sources may have significant contributions of local dust and dirt present within the snowpack [Doherty et al., 2016]. Relatively little dust is present in the NH snowpack. The estimated snowpack mean dust concentrations in both sampling seasons are typically 0.2 to 1 ppm [Adolph et al., 2016] based on $\mathrm{Ca}^{2+}$ concentrations [Polashenski et al., 2015]. This represents a conservative upper limit; $\mathrm{Ca}^{2+}$ is found in sea salt aerosol and is sourced from the treatment of roads with $\mathrm{CaCl}_{2}$ during particularly cold periods. Schwarz et al. [2012] find a positive offset of $15 \mathrm{ng} \mathrm{BC/g}$ liquid with 50 ppm dust in SP2 analysis but very little associated BC size distribution shift.

Black carbon in ambient snow is larger than found in the atmosphere and may experience an increase in size distribution during melt/freeze cycles [Schwarz et al., 2013], though the evidence for this is sparse. Lab experiments found that measured BC mass dropped by less than $5 \%$ in standards that were refrozen and later reanalyzed [Schwarz et al., 2013]. These results indicate that a small fraction of BC $(<5 \%)$ may agglomerate into larger particles [Schwarz et al., 2013]. However, this conclusion is based on standards that experienced one melt/freeze cycle [Schwarz et al., 2013]. Schwarz et al. [2013] go on to say that low BC concentrations $(<100 \mathrm{ppb})$ decrease the likelihood of mass agglomeration. Black carbon concentrations in $\mathrm{NH}$ are primarily less than $100 \mathrm{ppb}$. Therefore, an apparent mass loss due to agglomeration that causes a particle size increase to greater than $500 \mathrm{~nm}$ will not cause measurable error given the uncertainty associated with analysis ( $\pm 25 \%$ for USN/SP2 [Ohata et al., 2013]; $\pm 27 \%$ average USN/SP2 standard deviation in this study). Furthermore, Schwarz et al. [2012] and Wendl et al. [2014] note that they do not observe a significant shift in mass size distribution in snow samples that experience melt/refreeze cycles.

Loss of measured BC mass to HDPE container walls is another potential source of uncertainty if a sample is stored at room temperature for $24 \mathrm{~h}$ and later analyzed [Ogren et al., 1983; Schwarz et al., 2012]. Indeed, Kaspari et al. [2011] mention the apparent loss of BC mass to container walls. However, HDPE bottles only result in less than $10 \%$ variability in measured BC mass when compared to other bottle types (e.g., glass) when analyzed immediately following sonication [Wendl et al., 2014]. If samples are continuously frozen until analysis and sonicated just prior to analysis, as they were in this study, the use of HDPE bottles should not significantly impact results [Wendl et al., 2014]. 


\subsection{Data Processing}

\subsubsection{Impurity Inventory}

Data from the IC and SP2 are reported as concentration in melted snow, with units of $\mathrm{nmol} / \mathrm{L}$ and $\mathrm{ng} \mathrm{BC} / \mathrm{g}$ liquid (both hereby converted to parts per billion by weight (ppbw)), respectively. Inventory, or impurity burden per unit area, considers the water equivalence in a sample. Thus, inventory is a more consistent metric than concentration for snowpack impurity burden when SWE is changing. Inventories were calculated on a sample by sample basis using equation (1) (units in parentheses):

$$
\operatorname{lnv}_{j}\left(\frac{\mathrm{ng}}{\mathrm{cm}^{2}}\right)=[j]\left(\frac{\mathrm{nmol}}{\mathrm{L}}\right) \times M_{j}\left(\frac{\mathrm{g}}{\mathrm{mol}}\right) \times \frac{1}{1000}\left(\frac{\mathrm{L}}{\mathrm{g} \text { liquid }}\right) \times \operatorname{SWE}\left(\frac{\mathrm{g} \text { liquid }}{\mathrm{cm}^{2}}\right)
$$

where $j$ is a specific impurity contained in a single sample, [j] is impurity concentration, SWE is the sample SWE, and $M_{j}$ is the molar mass of each specific major ion. Because BC concentrations are already reported in $\mathrm{ng} / \mathrm{g}, M_{j}$ and the conversion from $\mathrm{L}$ to $\mathrm{g}$ liquid are omitted. Note that the density of meltwater is assigned $1000 \mathrm{~g} / \mathrm{L}$. All inventories are added over the complete snowpack profile for a given day to obtain daily integrated inventory and allow for evaluation of day-to-day impurity additions or losses regardless of SWE change.

\subsubsection{Quality Control}

The data set from both winters includes more than 2900 snow samples extracted from approximately 440 pits (seasonal specifics found in Table 1). Yearly data set from each site is screened to determine outliers. Tukey [1977] defines an outlier filter in which extreme outliers are flagged for further examination based on the equation below:

$$
[j]<\mathrm{IQR}_{j} \times 1.65+3 \mathrm{Q}_{j}
$$

where IQR is the interquartile range for a site data set and $3 Q_{j}$ is the value of the third quartile for a specific impurity. Tukey multiplies the IQR by the arbitrary value of 1.5 which we increase to 1.65 to include an approximation of $15 \%$ instrument error. This method is used to place bounds on a data set and flag data points that are extreme deviations. Therefore, this metric is only used to identify individual data points that seem anomalous to examine them further and determine their quality.

Generally, extreme outliers for most impurities occur in groups and can be plausibly explained by deposition of dust or other aerosols. For example, $\mathrm{Na}^{+}, \mathrm{Mg}^{2+}$, and $\mathrm{Ca}^{2+}$ outliers generally occur together in the same initial surface samples and can be traced for a period of time in subsequent snowpits. Therefore, they are attributed to dust or mineral deposition events. Similarly, outliers for $\mathrm{SO}_{4}{ }^{2-}$ and $\mathrm{NO}_{3}{ }^{-}$generally meet the same criteria as above and can be attributed to acidic aerosol deposition. Samples that are flagged as extreme outliers and show no evidence of heightened concentration in the same storm layer in preceding or following snowpits are further scrutinized. In the end, samples that have outliers for $\mathrm{K}^{+}, \mathrm{Na}^{+}$, and $\mathrm{Cl}^{-}$ are removed on the grounds of contamination from the person sampling or handling the sample in the lab. One or two samples at greatest snowpit depth are often orders of magnitude more concentrated in $\mathrm{K}^{+}$ than samples dispersed throughout the rest of the snowpack. These are thought to be contaminated by the soil surface beneath the snowpack and are also removed. For all sites in Winters 2 and 3, 1.8\% and $1.1 \%$ of samples are rejected due to human contamination, and $9.2 \%$ and $9.7 \%$ of samples are rejected due to soil contamination, respectively.

Samples that have been disqualified are not expected to greatly impact further analysis. Often, samples from the bottom of the snowpack have observations of debris or dirt in the sample indicating overzealous sampling resulting in extraordinary $\mathrm{K}^{+}$concentrations. Removing basal samples is equivalent to assuming that snow and impurities so close to the ground have left the snowpack. Samples that have been selectively removed due to human contamination do not have a significant effect on snowpack inventory calculated for any given pit, as the number of samples per snowpit on these days is usually large $(>10)$. Overall, a single sample containing at most $6 \mathrm{~cm}$ total depth contributes less to the snowpack inventory than is possible from other sources of uncertainty, though omission of these samples may introduce a low bias in a single integrated inventory.

\subsubsection{Identifying Periods of Active Melt}

Rapid snowpack changes accompany the onset of melt; therefore, objective identification of the start and duration of active melt is important. A linear weighted moving average [Ulrich, 2015] of five consecutive days 
Table 2. Average Coefficient of Variation for Seven NH Surveys ${ }^{a}$

\begin{tabular}{|c|c|c|c|c|}
\hline & SWE & $\mathrm{Cl}^{-}$ & $\mathrm{NO}_{3}{ }^{-}$ & BC \\
\hline CV (\%) & $8.7 \pm 4.2$ & $27 \pm 6.9$ & $24 \pm 4.2$ & $42 \pm 17$ \\
\hline
\end{tabular}

was applied to a full season of integrated SWE data to obtain a smoothed daily SWE profile. Smoothed SWE effectively removes spatial variability and allows for objective identification of downward trending SWE. Melt periods are considered active when the smoothed SWE profile decreases for at least 3 days in a row. The start day of the active melt cycle is then defined as the first day where a decrease in smoothed SWE was observed. The end of a melt cycle is when smoothed SWE trends up or the snowpack melts completely. Many previous field and lab studies that investigate the generation of an ionic pulse have defined the first melt fraction to be after 20-30\% SWE loss [Johannessen and Henriksen, 1978; Colbeck, 1981; Satoh et al., 1999; Williams et al., 2009]. In this study, measured SWE the day before melt began is defined as SWE at day $0\left(S_{W} E_{0}\right)$, and the ratio of subsequent integrated SWE divided by $\mathrm{SWE}_{0}$ is used to determine the first melt fraction, or when approximately $20 \%-30 \%$ SWE loss has occurred.

\subsubsection{Concentration Factors}

During times of active melt, we consider the most relevant physical process in the snowpack to be meltwater percolating down and out of the bottom of the snowpack. Therefore, any concurrent decrease in SWE and impurity inventory is interpreted as a release of water and impurities to the surrounding environment. We do not collect and directly measure the volume of meltwater leaving the snowpack, nor the impurity content in meltwater. However, daily sampling allows us to calculate the concentration of impurities in the meltwater. Since impurity and SWE additions to the snowpack may occur with rain and snow events during times of melt, calculated loss is a lower limit for what is physically lost from the snowpack. Meltwater concentrations cannot be calculated in instances where SWE and impurity inventory do not decrease concurrently, though negative losses (impurity inventory gains) are calculated when inventory increases coincident with decreasing SWE. The concentration of each impurity leaving the snowpack in meltwater is calculated with equation (3):

$$
[j]_{\text {meltwater }}\left(\frac{\mathrm{ng}}{\mathrm{g}}\right)=\Delta \operatorname{lnv}_{j}\left(\frac{\mathrm{ng}}{\mathrm{cm}^{2}}\right) \times \frac{1}{\Delta \mathrm{SWE}}\left(\frac{\mathrm{cm}^{2}}{\mathrm{~g} \text { liquid }}\right)
$$

where $\Delta \operatorname{lnv}_{j}$ is the calculated integrated inventory change from 1 day to the next and $\triangle S W E$ is integrated SWE change from 1 day to the next. Calculated meltwater concentrations are in units of $\mathrm{ng} / \mathrm{g}$ (ppbw). A small decrease in SWE accompanied by a decrease in impurity inventory will result in a large calculated meltwater concentration. This is a common finding in field and laboratory snowmelt studies that use lysimeters or snow columns to analyze major ions in meltwater. Calculated meltwater concentration divided by the average concentration in the snowpack at the beginning of melt yields a concentration factor (CF; unitless) [Johannessen and Henriksen, 1978].

\section{Results}

\subsection{Spatial Variability}

Spatial variability estimates aid in determining which snowpack chemistry changes reflect temporal changes as opposed to changes in chemistry due to sampling in a different location each day. Two to nine pits were sampled in succession on seven different days throughout both sampling campaigns. Meter scale variability of $\mathrm{Cl}^{-}$and $\mathrm{NO}_{3}{ }^{-}$observed in $\mathrm{NH}$ seasonal snow (Table 2) are similar to coefficients of variance reported for Greenland snow [Hart, 1997; Dibb and Jaffrezo, 1997]. Meter scale variability of BC in NH (Table 2) is also in accord with values for elemental carbon in surface snow of Arctic Finland reported by Svensson et al. [2013] and values reported in Doherty et al. [2010, 2014, 2016]. The variability of SWE at our study sites (Table 2) is lower than the average SWE variability for six Greenland surveys reported in Hart [1997].

\subsection{Seasonal Overviews}

Since concentration cannot be less than 0 , mass and concentration distributions of constituents in snow tend to be positively skewed. Thus, the median is the best measurement of central tendency for intersite and 


\begin{tabular}{lcccc}
$\begin{array}{l}\text { Table 3. Median } \mathrm{BC}_{1} \mathrm{Cl}^{-}, \mathrm{NO}_{3}{ }^{-\mathrm{a}} \text {, and Sample Density } \\
\text { Winter/Site }\end{array}$ & $\mathrm{Cl}^{-}$(ppbw) & $\mathrm{NO}_{3}{ }^{-}$(ppbw) & Density $\left(\mathrm{g} / \mathrm{cm}^{3}\right.$ ) \\
\hline & 5.60 & Winter 3 & \\
DFO & 3.90 & 563 & 514 & 0.27 \\
BDO & 129 & 415 & 0.24 \\
TFO & 163 & 461 & 0.25 \\
& & & \\
CYO & 11.0 & 185 & 420 & 0.23 \\
BDO & 6.67 & 151 & 240 & 0.24 \\
TFO & 6.61 & 144 & 270 & 0.25 \\
\hline
\end{tabular}

${ }^{\mathrm{a}}$ Median concentrations are calculated over a full season of individual sample data after quality control.

interstudy comparison. Median $\mathrm{Cl}^{-}$concentration at DFO during Winter 3 is about $400 \%$ higher than median $\mathrm{BDO} / \mathrm{TFO} \mathrm{Cl}{ }^{-}$concentrations, while median $\mathrm{NO}_{3}{ }^{-}$concentrations across the state are similar (Table 3). Given that sea salt aerosol deposition rapidly decreases with distance from the coastline [Gustafsson and Franzén, 1999; Liang et al., 2016], there appears to be a strong source of non-sea salt $\mathrm{Cl}^{-}$at DFO in Winter 3.

Median $\mathrm{Cl}^{-}$concentration at CYO during Winter 2 is only slightly higher than at BDO/TFO (Table 3), while $\mathrm{NO}_{3}{ }^{-}$concentration at $\mathrm{CYO}$ is about $150 \%$ higher than at $\mathrm{BDO} / \mathrm{TFO}$. Overall, $\mathrm{Cl}^{-}$and $\mathrm{NO}_{3}{ }^{-}$concentrations in $\mathrm{NH}$ are much lower than $\mathrm{Cl}^{-}$[Oliver et al., 1974], and $\mathrm{NO}_{3}{ }^{-}$[Bock and Jacobi, 2010] concentrations reported for urban snow collected from rooftops but much higher than median concentrations reported for remote Greenland [Dibb et al., 2007].

Median BC concentrations at CYO/DFO are always higher than concentrations at BDO/TFO (Table 3). Black carbon in snow at DFO is $15 \%$ more concentrated than at BDO/TFO in Winter 3, and $60 \%$ more concentrated at CYO than at BDO/TFO in Winter 2. Overall, median BC concentrations in NH snow are similar to mean concentrations reported for remote Sierra Nevada sites [Hadley et al., 2010] and some Arctic sites [Doherty et al., 2010] and are higher than mean concentrations reported for remote sites in Greenland [Polashenski et al., 2015]. In contrast, BC concentrations at sites with similar elevation and latitude in the Northern U.S. Plains [Doherty et al., 2014] are typically much higher than BC concentrations in NH. However, seasonal median concentrations that include samples during times of melt are not the best comparison to Doherty et al. [2014] as they typically obtained a single sample at near max SWE before snowmelt.

Major ions and BC at maximum SWE (Table 4) reflect the main site and campaign differences outlined in the description accompanying Table 3, which indicates that observations of impurity concentrations during SWE maximum can be representative of a region in some cases. Note that $\mathrm{BC}$ concentrations reflect spatial differences noted in the above paragraph, while BC inventory at BDO/TFO during Winter 3 is comparable to $B C$ inventory at DFO. This is due to less snow water and more BC inventory at DFO, which leads to higher concentrations. In contrast, average BC concentration at max SWE at CYO in Winter 2 is 300\%-500\% greater than at BDO/TFO despite CYO having 200\% more snow water at max SWE (Table 4). This may be caused by the temporal difference in maximum SWE at each location. Thus, caution is needed when a single pit is assumed to represent a site for a winter season rather than just on the day when the pit was sampled.

Table 4. Maximum Integrated SWE, Integrated Inventory, and Average Concentration ${ }^{\mathrm{a}}$ at Maximum SWE

\begin{tabular}{lccccc} 
Winter/Site & Date & $\mathrm{SWE}\left(\mathrm{g} / \mathrm{cm}^{2}\right)$ & $\mathrm{BC}\left(\mathrm{ng} / \mathrm{cm}^{2}\right)(\mathrm{ppbw})$ & $\mathrm{Cl}^{-}\left(\mathrm{ng} / \mathrm{cm}^{2}\right)(\mathrm{ppbw})$ & $\mathrm{NO}_{3}{ }^{-}\left(\mathrm{ng} / \mathrm{cm}^{2}\right)(\mathrm{ppbw})$ \\
\hline & & Winter 3 & \\
DFO & $3 \mathrm{Mar}$ & 11.10 & $71(6.4)$ & $13100(1180)$ & $11400(1030)$ \\
BDO & $22 \mathrm{Feb}$ & 14.89 & $69(4.6)$ & $5210(350)$ & $10700(719)$ \\
TFO & $5 \mathrm{Mar}$ & 16.09 & $75(4.7)$ & $6880(429)$ & $12800(794)$ \\
& & Winter 2 & \\
CYO & $13 \mathrm{Mar}$ & 14.37 & $350(24)$ & $3580(249)$ & $8000(557)$ \\
BDO & $21 \mathrm{Feb}$ & 6.99 & $54(7.7)$ & $1110(158)$ & $1930(275)$ \\
TFO & $22 \mathrm{Feb}$ & 7.90 & $34(4.3)$ & $762(96.4)$ & $1440(182)$
\end{tabular}

\footnotetext{
${ }^{a}$ Average snowpack concentration is calculated with integrated inventory and maximum integrated SWE similar to
} equation (3). 


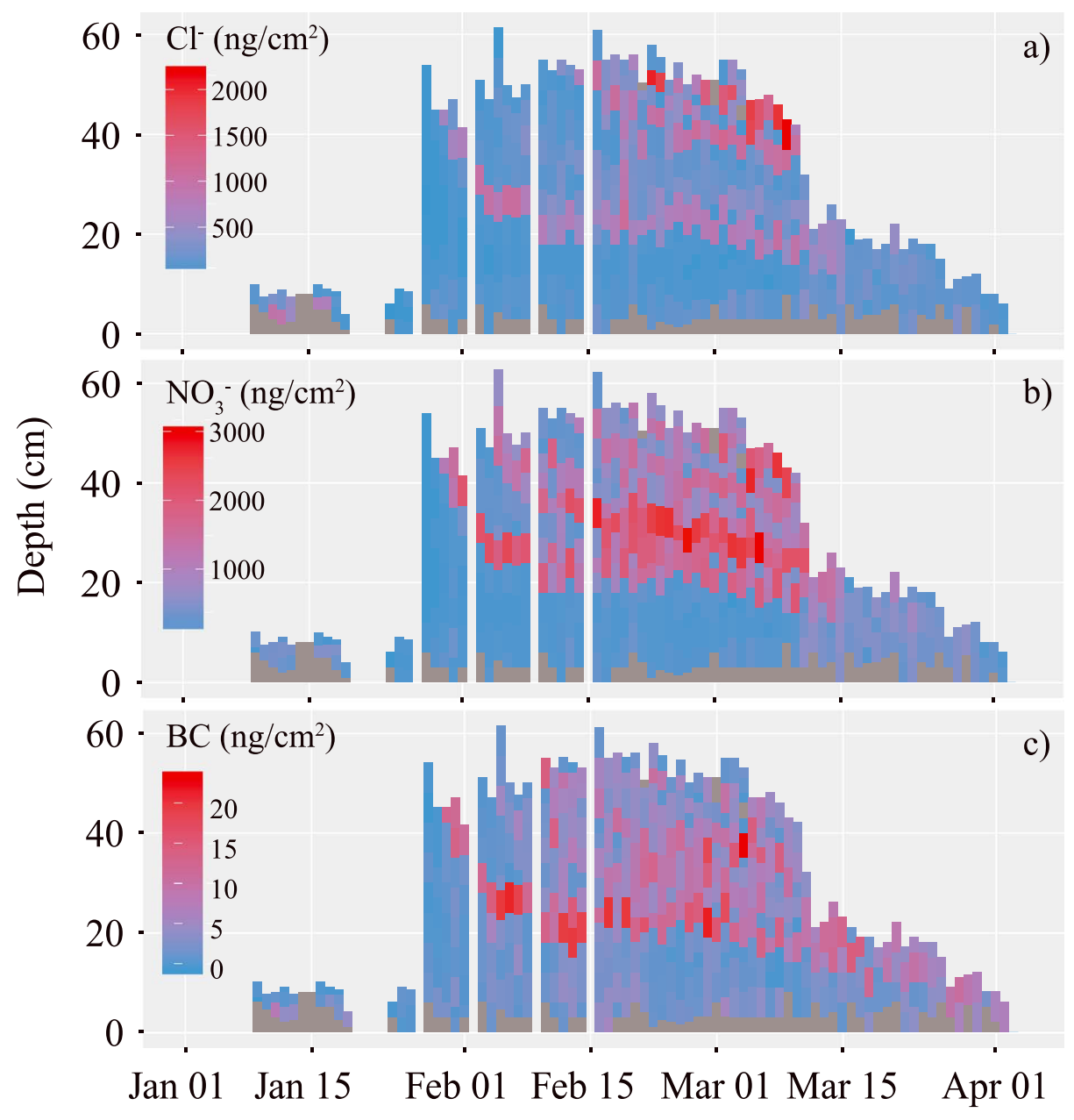

Figure 2. Inventory (relative amounts denoted with color) for (a) $\mathrm{Cl}^{-}$, (b) $\mathrm{NO}_{3}{ }^{-}$, and (c) $\mathrm{BC}$, plotted against sample depth during Winter 3 at BDO. The days with no inventory data in the middle of January are days where the snowpack completely melted, whereas the 4 days from the end of January to the middle of February are days where heavy snowfall prevented sampling. Each dark shaded box (typically near the bottom of the snowpack) represents samples that have been removed according to the QC protocol outlined in 2.5.2.

Measured integrated SWE from Doherty et al. [2014] is comparable to seasonal maximum SWE measured in $\mathrm{NH}$; however, integrated $\mathrm{BC}$ in $\mathrm{NH}$ (Table 4) is typically much lower than estimates of integrated $\mathrm{BC}$ in central North America. The only Doherty et al. [2014] sites that have much lower integrated BC than in NH are 31-34, but these sites are samples of only newly fallen snow on bare ground with intermittent snow cover and are likely not representative of all the Northern U.S. Plains sites. Samples 1, 3a, 6, 8, 11, 12b, 13, 57c, and 63c in Doherty et al. [2014] have comparable integrated BC to $\mathrm{NH}$, though many of these sites also include notes of fresh surface snow and are taken in forests or mountain passes. Doherty et al. [2014] sites 4, 40, 42, and 47 are all far above even Winter 2 CYO integrated BC in NH (Table 4), but site 4 was sample from a drift, and site 42 was sampled near the Bakken oil fields in North Dakota. Sites 40 and 47 in Doherty et al. [2014] have high estimates of non-BC particles ( 40\%), which the authors suggest may lead to an overestimation of snowpack BC due to potentially uncorrected method biases.

Time series analysis of each pit during Winter 3 at BDO, which is the most comprehensive data set, reveals snow layers with distinct impurity inventories that persist through most of the winter (Figure 2). Air temperature at BDO during the month of February was low enough that the snowpack did not undergo noticeable diurnal melting and freezing; thus, no ice layers were recorded in the snowpack until early March. A light snowfall on 29 January had high inventory of all three impurities, causing a marked increase in surface inventory (Figure 2). The next snowfall on 2 February buried this layer with relatively clean snow. Note that 


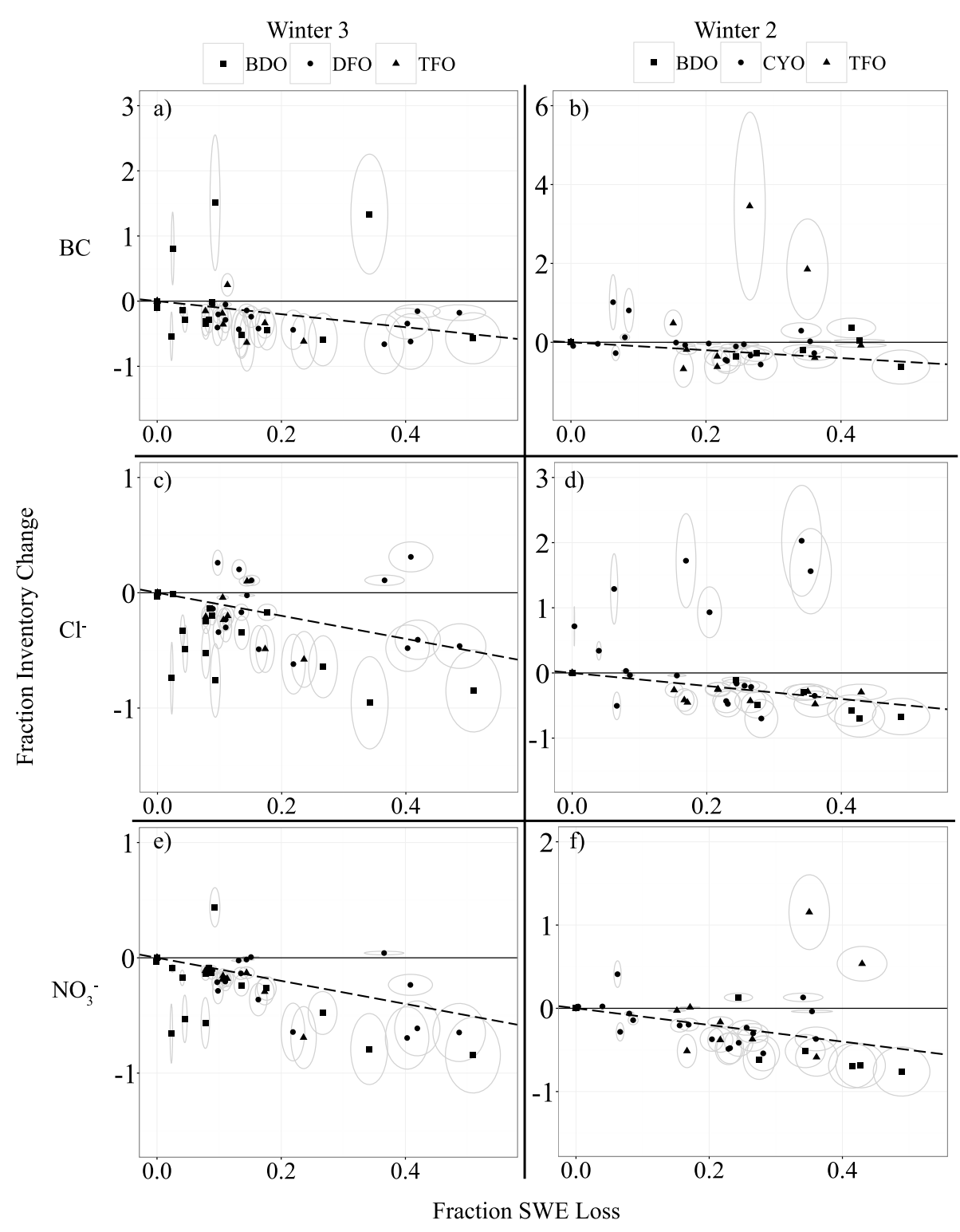

Figure 3. Daily $(\mathrm{a}, \mathrm{b}) \mathrm{BC}$ loss, $(\mathrm{c}, \mathrm{d}) \mathrm{Cl}^{-}$loss, and $(\mathrm{e}, \mathrm{f}) \mathrm{NO}_{3}{ }^{-}$loss at all sites during the first fraction of melt in Winters 3 and 2. Sites are denoted by symbol in the legend at the top of the plot. The dashed line $(y=-x)$ indicates 1:- 1 SWE loss to impurity inventory loss. The line at $y=0$ indicates steady impurity inventory during SWE loss. Instrument error and spatial variability are denoted by the ellipse drawn around each data point.

the layer including the 29 January snow remained discernible as subsequent snow events buried it deeper until the major melt began in early March. Similarly, snow events on 5 and 15 February can be traced from pit to pit until melting begins, and chemical stratigraphy becomes less distinct. Generally, water equivalent depth of each distinguishable snowpack layer did not change from deposition until melt in March (not shown).

\subsection{First Fraction of Melt}

The snowpack accumulates impurities throughout the season (Figure 2) and releases them as meltwater during an active melt period. The first melt fractions were objectively determined (see section 2.5.3) and impurity inventories traced at each site during Winters 2 and 3. To put changes in inventory into context with changes in $\mathrm{SWE}, \Delta \mathrm{Inv}$ for $\mathrm{BC}, \mathrm{Cl}^{-}$, and $\mathrm{NO}_{3}{ }^{-}$are plotted versus $\Delta \mathrm{SWE}$ (Figure 3). Each $\Delta \mathrm{Inv}$ and $\Delta \mathrm{SWE}$ are relative to their respective values at the corresponding $S_{W} E_{0}$. 
Table 5. Percent and Absolute Inventory Changes During First Fraction of SWE Loss ${ }^{\mathrm{a}}$

\begin{tabular}{|c|c|c|c|c|c|c|c|c|}
\hline & SWE (\%) & $\Delta \operatorname{lnv}\left(\mathrm{g} / \mathrm{cm}^{2}\right)$ & $\mathrm{Cl}^{-}(\%)$ & $\Delta \operatorname{lnv}\left(\mathrm{ng} / \mathrm{cm}^{2}\right)$ & $\mathrm{NO}_{3}{ }^{-}(\%)$ & $\Delta \operatorname{lnv}\left(\mathrm{ng} / \mathrm{cm}^{2}\right)$ & BC (\%) & $\Delta \operatorname{lnv}\left(\mathrm{ng} / \mathrm{cm}^{2}\right)$ \\
\hline Winter 3 & DFO & & & & & & & \\
\hline $22-26 \operatorname{Jan}^{\mathrm{b}}$ & $41 \pm 6$ & 2.02 & $-31 \pm 56$ & 537 & $23 \pm 30$ & 174 & $62 \pm 19$ & 21.1 \\
\hline 3-13 Mar & $22 \pm 8$ & 2.43 & $62 \pm 16$ & 8120 & $64 \pm 14$ & 7350 & $44 \pm 27$ & 31.0 \\
\hline \multirow[t]{2}{*}{$23-26 \mathrm{Mar}$} & $49 \pm 5$ & 5.05 & $46 \pm 23$ & 2520 & $65 \pm 14$ & 3530 & $18 \pm 38$ & 9.40 \\
\hline & $B D O$ & & & & & & & \\
\hline 16-19 Jan & $34 \pm 7$ & 0.55 & $95 \pm 2$ & 766 & $79 \pm 8$ & 429 & $-130 \pm 120$ & 2.88 \\
\hline 3-11 Mar & $27 \pm 7$ & 3.61 & $64 \pm 15$ & 3560 & $48 \pm 21$ & 5550 & $59 \pm 21$ & 42.3 \\
\hline \multirow[t]{2}{*}{$23-27 \mathrm{Mar}$} & $51 \pm 5$ & 4.86 & $85 \pm 6$ & 755 & $84 \pm 6$ & 1720 & $57 \pm 21$ & 13.5 \\
\hline & TFO & & & & & & & \\
\hline 17-18 Jan & $24 \pm 8$ & 0.42 & $58 \pm 18$ & 115 & $69 \pm 12$ & 709 & $62 \pm 22$ & 7.23 \\
\hline 5-10 Mar & $17 \pm 8$ & 2.79 & $49 \pm 22$ & 3350 & $29 \pm 28$ & 3740 & $34 \pm 34$ & 25.2 \\
\hline $23-25 \mathrm{Mar}$ & $15 \pm 8$ & 1.23 & $-15 \pm 49$ & 178 & $-3 \pm 41$ & 107 & $46 \pm 25$ & 34.3 \\
\hline Winter 2 & $\mathrm{CYO}$ & & & & & & & \\
\hline 6-10 Jan & $26 \pm 8$ & 1.03 & $19 \pm 35$ & 142 & $23 \pm 30$ & 288 & $5 \pm 44$ & 1.99 \\
\hline $21-27 \mathrm{Jan}$ & $35 \pm 6$ & 1.07 & $-150 \pm 100$ & 754 & $4 \pm 38$ & 103 & $-2 \pm 46$ & 0.74 \\
\hline 3-9 Mar & $9 \pm 9$ & 0.44 & $3 \pm 41$ & 71.6 & $14 \pm 34$ & 492 & $-81 \pm 84$ & 30.1 \\
\hline $21-27 \mathrm{Mar}$ & $17 \pm 8$ & 2.13 & $-170 \pm 120$ & 3020 & $20 \pm 32$ & 1960 & $7 \pm 41$ & 18.9 \\
\hline \multirow[t]{2}{*}{ 1-4 Apr } & $36 \pm 6$ & 3.82 & $35 \pm 28$ & 1100 & $37 \pm 25$ & 1200 & $27 \pm 32$ & 54.3 \\
\hline & $B D O$ & & & & & & & \\
\hline 6-7 Jan & $42 \pm 6$ & 2.01 & $58 \pm 18$ & 691 & $69 \pm 12$ & 981 & $-36 \pm 62$ & 11.0 \\
\hline $22-24 \mathrm{Feb}$ & $49 \pm 5$ & 3.06 & $67 \pm 14$ & 620 & $76 \pm 10$ & 1040 & $63 \pm 19$ & 27.3 \\
\hline \multirow[t]{2}{*}{ 7-12 Mar } & $43 \pm 6$ & 2.47 & $69 \pm 13$ & 1050 & $69 \pm 12$ & 1500 & $-4 \pm 46$ & 2.49 \\
\hline & TFO & & & & & & & \\
\hline $6-8$ Jan & $43 \pm 6$ & 1.95 & $30 \pm 30$ & 138 & $-54 \pm 61$ & 96.7 & $8 \pm 55$ & 0.73 \\
\hline 26-30 Jan & $36 \pm 6$ & 0.65 & $48 \pm 22$ & 601 & $59 \pm 16$ & 490 & $39 \pm 28$ & 6.24 \\
\hline 10-14 Mar & $26 \pm 7$ & 2.01 & $43 \pm 24$ & 748 & $37 \pm 25$ & 1070 & $-340 \pm 200$ & 72.6 \\
\hline
\end{tabular}

${ }^{\mathrm{a}}$ Plus/minus percent uncertainty is spatial variability and instrument error.

${ }^{b}$ Each date range listed corresponds to a first melt fraction.

In Winter $3 \mathrm{Cl}^{-}$and $\mathrm{NO}_{3}{ }^{-}$inventories consistently decrease at a quicker rate than SWE (Figures $3 \mathrm{c}$ and $3 \mathrm{e}$ ). This result is expected given the wide body of literature on the ionic pulse [Johannessen et al., 1976; Johannessen and Henriksen, 1978; Hibberd, 1984; Williams and Melack, 1991; Bales et al., 1989; Harrington and Bales, 1998a, 1998b; Satoh et al., 1999; Feng et al., 2001; Lee et al., 2008; Williams et al., 2009]. There are a few exceptions (i.e., points above the 1:-1 line), which is indicative of impurity inventory gain during melt. However, most major ion inventory losses in Winter 3 fall below the 1:-1 line, indicating a high major ion meltwater scavenging efficiency.

In Winter 2, major ion inventories also decrease quicker than SWE (Figures 3d and 3f) but not with the same clarity as in Winter 3. There are noticeable impurity inventory gains to the melting snowpack. Specifically, $\mathrm{Cl}^{-}$ at CYO has high-fractional gains during melt, but this may be due to the location of CYO relative to the CRREL parking lot (see Figure 1 in Adolph et al. [2016]). Additionally, $\mathrm{NO}_{3}{ }^{-}$has high fractional gains at BDO/TFO, but this may be an artefact of incomplete snowpack sampling or low temporal resolution compared to Winter 3 (Table 1).

Black carbon is generally thought to have a lower meltwater scavenging efficiency than major ions [Colbeck, 1981; Doherty et al., 2013]; however, many BC inventory losses plot beneath the 1:-1 line in both Winters 3 (Figure 3a) and 2 (Figure 3b). There are some BC inventory gains during melt, which can plausibly be caused by wet or dry deposition onto a thin snowpack. Deposition of BC to a thin snowpack with low BC inventory will cause a large positive fractional inventory change.

Fractional inventory changes during Winter 3 indicate that major ions and BC share similar properties during the onset of melt. Therefore, a fraction of snowpack $\mathrm{BC}$ in $\mathrm{NH}$ is efficiently scavenged by meltwater. Observations of $\mathrm{BC}$ loss in the melting $\mathrm{NH}$ snowpack are supported by observations of hydrophilic and hydrophobic soot loss in a snowpack at Snowdome [Conway et al., 1996]. In these experiments, over 50\% of hydrophobic soot and nearly all hydrophilic soot were flushed through the snowpack in a 10 day melt period [Conway et al., 1996]. 


$$
\rightarrow \mathrm{Cl}^{-} \rightarrow \mathrm{NO}_{3}^{-} \rightarrow \mathrm{BC} \quad-\mathrm{SWE}\left(\mathrm{g} / \mathrm{cm}^{2}\right)
$$

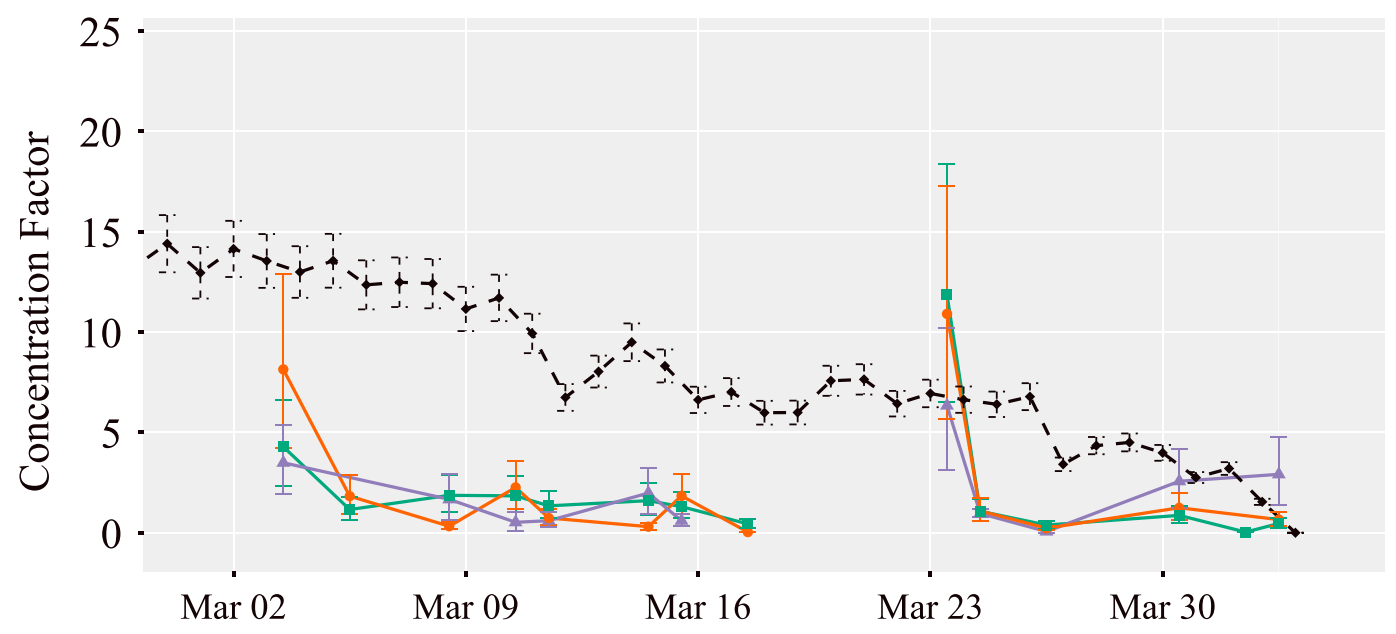

Figure 4. Concentration factor (CF) of snowpack meltwater over time for March of Winter 3 at BDO. Error bars include spatial variability and instrument error. The two separate melt events beginning on 3 and 23 March best replicate the ionic pulse observed in laboratory settings, where the highest meltwater concentration is at the onset of melt. Note that calculated BC meltwater concentrations are also highest at the onset of melt events, with CF of $\sim 3$ and $\sim 7$ for the first and second events, respectively. CF is not continuous due to an increase in smoothed SWE calculated in between records (see section 2.5.3).

\subsection{Impurity Pulse}

Absolute SWE and impurity inventory changes over the first fraction of melt also indicate that BC is lost with comparable efficiency to major ions in some cases (Table 5). Early March impurity inventories decrease quicker than SWE in Winter 3 in every case, with most impurity inventories decreasing by over $40 \%$ with $20 \%$ SWE loss (Table 5). Considering all cases in Winter 3, inventory decreases quicker than SWE in six of nine cases for $\mathrm{Cl}^{-}$, seven of nine cases for $\mathrm{NO}_{3}{ }^{-}$, and seven of nine cases for $\mathrm{BC}$.

In Winter 2, impurity inventory decreases quicker than SWE in only 5 of 11 cases for $\mathrm{Cl}^{-}, 7$ of 11 cases for $\mathrm{NO}_{3}{ }^{-}$, and two of nine cases for $\mathrm{BC}$ (Table 5). The snowpack in Winter 2 experienced more inventory changes of a smaller magnitude (Table 5). This leads to a lower signal-to-noise ratio and larger uncertainty. Additionally, the Winter 2 data set has notable shortcomings-primarily missed sampling days (Table 1) and sporadic incomplete snowpack sampling. Hence, the Winter 2 data set is not of sufficient quality to calculate a CF time series.

Concentration factor time series during the last two melt events at BDO during Winter 3 (Figure 4) share some similar features of laboratory experiments detailing a solute pulse. The most noticeable similarity is that the highest calculated meltwater concentration is on the first day of melt [Johannessen and Henriksen, 1978; Colbeck, 1981; Bales et al., 1989]. Concentration factors for $\mathrm{Cl}^{-}$and $\mathrm{NO}_{3}{ }^{-}$in each event are initially so large because of the relatively small amount of water and large amount of impurity inventory that left the snowpack. As the melt continues, CF for every impurity drops to or below 1.0. Using equation (3), peak calculated meltwater concentrations are 3.7 and 3.3 ppmw for nitrate and chloride, respectively, in the first event, and 3.5 and 1.4 ppmw for the second event. BC has peak calculated meltwater concentrations of 18 and 22 ppbw for the same two March events.

\section{Discussion}

\subsection{Spatial Differences}

Some of the observed differences in median impurity concentrations across NH were not anticipated. In particular, enhanced deposition of $\mathrm{Cl}^{-}$at CYO/DFO compared to BDO/TFO was not expected (Table 3). This is counterintuitive if the main source of $\mathrm{Cl}^{-}$is sea salt aerosol. Short range transport of road deicing agents from the state highway just to the east and/or the interstate across the river may increase $\mathrm{Cl}^{-}$in snow 

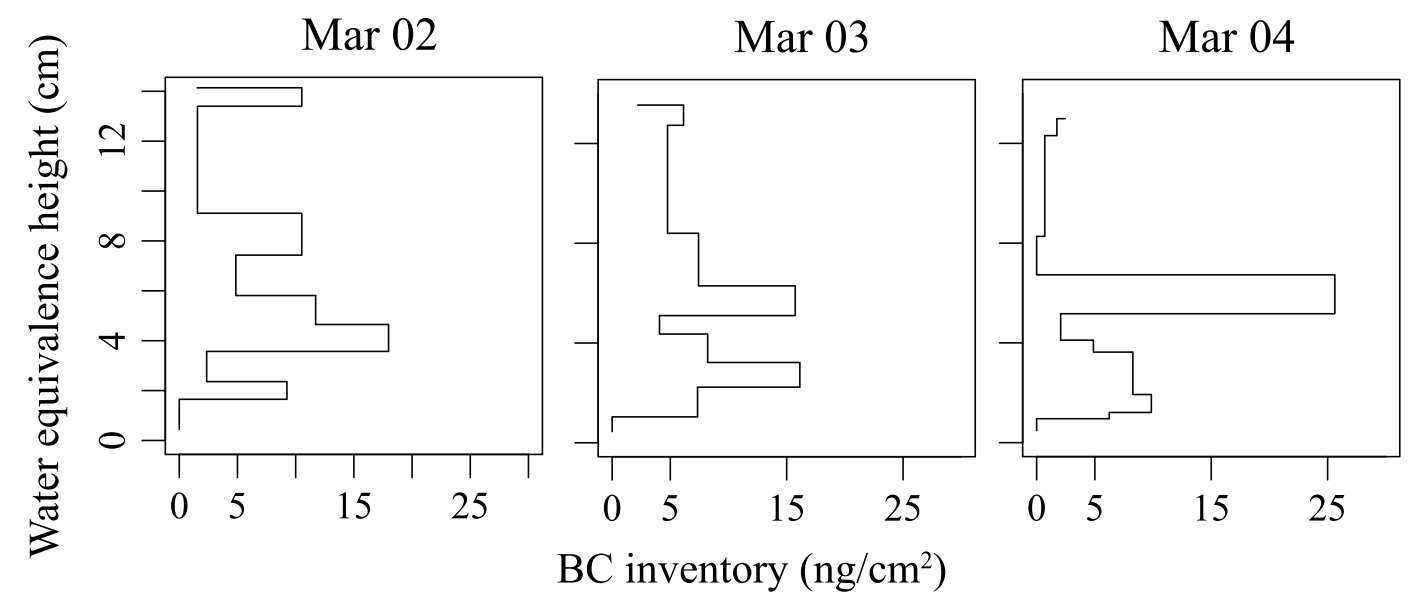

Figure 5. BC inventory on the day before snowmelt (2 March) to the day after the start of melt (4 March) at BDO in Winter 3 plotted against water equivalence height. Inventory at the top of the snowpack decreases, while inventory at middle and lower heights increases.

at CYO/DFO [Lundmark and Olofsson, 2007]. Other differences may be explained by atmospheric transport pathways. Adolph et al. [2016] show that weather systems bringing snow to CYO/DFO originate over land to the west, while coastal or sea-based storms are responsible for most snowfall at BDO/TFO. Higher concentrations and inventories of $B C$ at CYO/DFO may reflect greater industrial emissions upwind, especially compared to storms approaching BDO/TFO from offshore. High traffic volume of diesel vehicles passing nearby may be another factor enhancing BC deposition at CYO/DFO [U.S. EPA, 2009]. Wood burning stoves for heating may lead to increased $B C$ concentration in snow as well. Up to $30 \%$ of homes primarily burn wood for heat in Grafton County (CYO/DFO) compared to $0.1-5.0 \%$ in Strafford County (BDO/TFO) [Finamore, 2013].

\subsection{Impurity Pulse}

The behavior of $\mathrm{BC}$ during the first melt fraction is similar to the traditional ionic pulse measured in snowmelt. At BDO in Winter 3, the time series of calculated concentration factor for $\mathrm{BC}$ is quite similar to those for $\mathrm{Cl}^{-}$ and $\mathrm{NO}_{3}{ }^{-}$(Figure 4), indicating that $\mathrm{BC}$ is washed from the snowpack at a similar rate as these ions. We did not quantify the specific chemistry of $B C$ particles, but it is possible that some particles containing $B C$ have hydrophilic components or coatings, which could facilitate their transport by meltwater percolating from the surface of the snowpack.

Conway et al. [1996] found that both hydrophobic and hydrophilic submicron soot applied to the surface of a ripe springtime snowpack decreased in concentration by at least two orders of magnitude over 3 days of melting. By the end of this experiment, hydrophobic soot migrated into and through the snowpack, with just over $50 \%$ of soot applied in a $2.5 \mathrm{~cm}$ surface layer migrating out of the bottom of the pack. The remainder was retained within $28 \mathrm{~cm}$ of the surface. Hydrophilic soot, however, was almost entirely flushed from the snowpack, with just $1 \%$ of the initial surface application retained in the snowpack [Conway et al., 1996]. In the present study, 59\% of BC mass at BDO in Winter 3 was flushed out of the snowpack with the first $27 \%$ of melt during early March (Table 5). This early part of the melt also transferred much of the $41 \%$ of BC that remained in the snowpack to deeper layers at the end of the 3 day interval (Figure 5). It is important to note that redistribution of $B C$ with little or no change in SWE can occur if the snowmelt from the surface refreezes in the middle of the snowpack. Colbeck [1981] described a similar phenomenon for a snowpack doped with sodium chloride in various layers, where impurities migrate and concentrate in lower layers prior to being flushed completely out of the snowpack.

The maximum $B C$ concentration factor at DFO during the early March melt in Winter 3 is larger by three to five times than those observed at BDO (Figure 6 compared to Figure 4). Calculated concentration factors for BC at TFO (not shown) were similar to those at BDO. It should be noted that we were not able to calculate concentration factors for ions at DFO for the first week of this melt event because their inventories did not monotonically decrease until the last 4 days (Figure 6). This is a combined result of spatial variability within the snowpack and impurity additions to the surface of the snowpack outweighing small losses early in the 


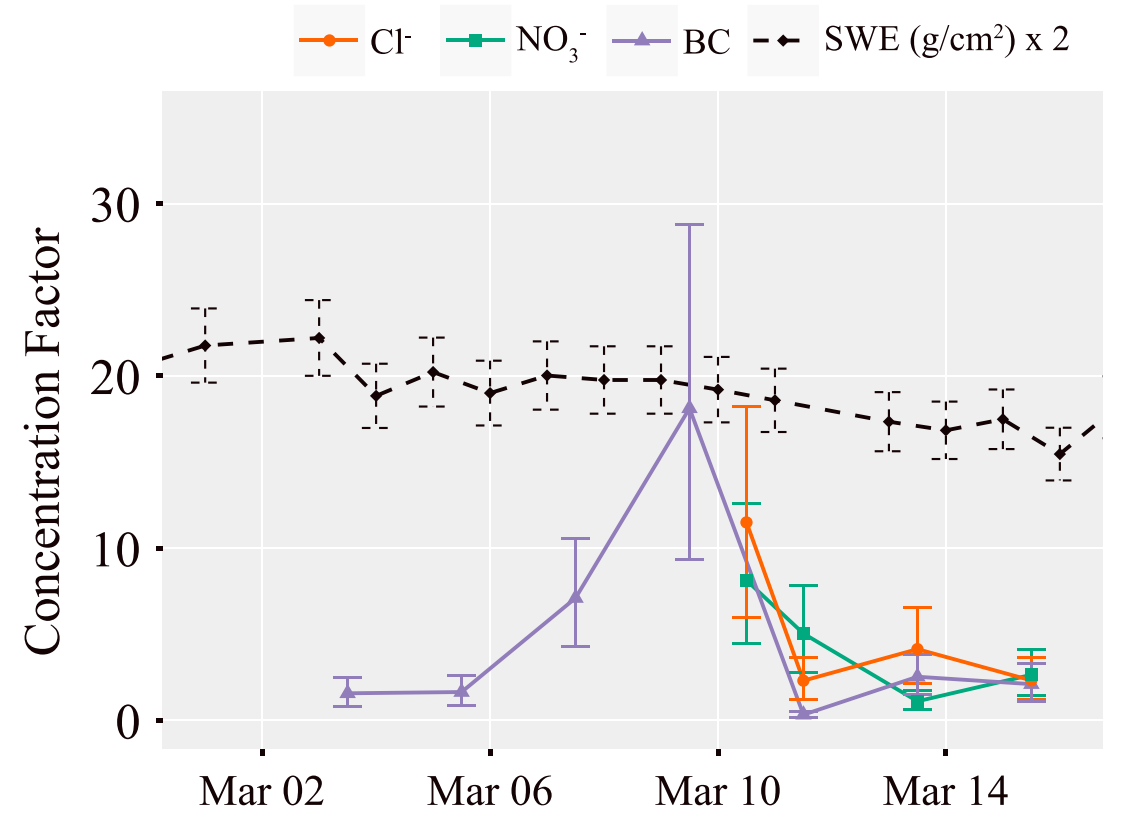

Figure 6. Concentration factor (CF) of snowpack meltwater over time for early to mid-March in Winter 3 at DFO. Error bars include spatial variability and instrument error. SWE is scaled by a factor of 2 for clarity.

melt. While we do not suggest that $\mathrm{BC}$ in snow at DFO is more mobile than $\mathrm{Cl}^{-}$and $\mathrm{NO}_{3}{ }^{-}$during the early melt, it does seem that $\mathrm{BC}$ at $\mathrm{DFO}$ was more mobile than $\mathrm{BC}$ at $\mathrm{BDO}$ and TFO. Longer aerosol transport times [Adolph et al., 2016] suggest that DFO receives BC that has had more time to react with strong oxidizing agents in the atmosphere (e.g., ozone) thus functionalizing the surface [Sergides et al., 1987]. Longer aerosol transport times could also lead to a decrease in particle size as heavier particles are more likely to drop out [Liang et al., 2016].

Shortly after the peak calculated BC concentration factor values drop to near 1.0 (Figures 4 and 6), indicating a change in the effectiveness or rate of $B C$ flushing. The abrupt change in the rate of $B C$ loss late in active melt indicates that at least two large categorical fractions exist in the $\mathrm{NH}$ snowpack: one fraction that flushes readily with small amounts of melt water (approximately 44\% [59\%] BC loss with 22\% [27\%] SWE loss for DFO [BDO] in Winter 3 (Table 5)) and a second fraction that is flushed less readily or remains behind. Chloride and nitrate also show a decrease in effective loss rate, which has been attributed to exclusion of impurities to ice grain boundaries [Colbeck, 1981; Bales et al., 1989; Kuhn, 2001]. This makes a large fraction of the ion burden readily available for transport in early percolating meltwater, while a small fraction of ions incorporated in the ice lattice are immobile until more advanced melt. It is possible that seasonal snowpacks exclude most BC from aging grains similar to major ions, but this has not been tested or experimentally verified.

Some BC leaves the snowpack faster than SWE (Figure 3), and BC losses can be as large as major ion losses (Table 5) during an active melt period. The reason $\mathrm{BC}$ in the $\mathrm{NH}$ snowpack is nearly as mobile as soluble impurities is not known but could involve hydrophilic $B C$ surfaces/coatings and/or mobilization of a smaller diameter fraction. Black carbon number and mass distribution modes during the 5 day January melt at DFO in Winter 3 (62\% BC mass loss and 41\% SWE loss (Table 5)) reveal no substantial change in particle diameter in the surface layer or overall snowpack. The surface $B C$ number concentration mode increased from $75 \mathrm{~nm}$ to $85 \mathrm{~nm}$, while the surface $B C$ mass concentration mode decreased from $220 \mathrm{~nm}$ to $200 \mathrm{~nm}$. Neither change is statistically significant given the uncertainty. The number concentration mode for this case is only slightly larger than the soot used by Conway et al. [1996] $(60 \mathrm{~nm}$ for hydrophobic soot; data for hydrophilic soot not given) in their controlled study. The evidence presented above along with evidence of storm aerosol origin and transport presented in Adolph et al. [2016] suggests that BC particle coatings or functionalization is the main contributor to the behavior of $B C$ in $\mathrm{NH}$ snow, though further research on $\mathrm{NH}$ snowpack $\mathrm{BC}$ particle coatings and particle and $\mathrm{BC}$ size is needed to confirm. 


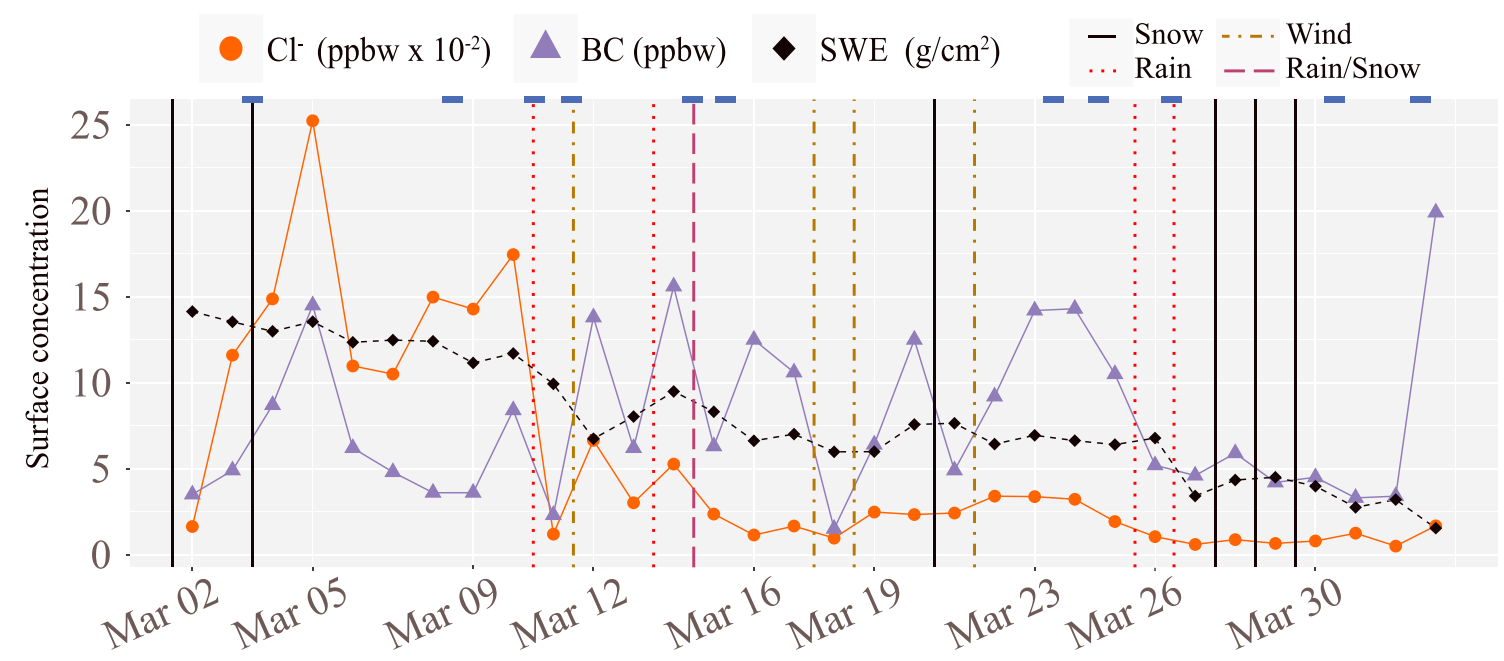

Figure 7. Snow water equivalence and surface concentrations for $\mathrm{Cl}^{-}$and $\mathrm{BC}$ during last month of Winter 3 sampling at BDO. Observed snowfall is marked by the black solid line, rainfall by the red dotted line, excessive wind by the dark yellow dash-dotted line, and rain/snow mix by the long dash line. Blue marks at the top of the plot indicate when integrated BC inventory and SWE are decreasing. Error bars have been excluded for clarity.

\subsection{Prolonged Melt Impurity Dynamics}

Many studies focus on the melt amplification of surface BC during times of SWE loss from the snowpack through a combination of melt, sublimation, and dry deposition [Hansen and Nazarenko, 2004; Doherty et al., 2010; Aamaas et al., 2011; Xu et al., 2012; Doherty et al., 2013; Svensson et al., 2013; Tedesco et al., 2016]. A close examination of BC concentrations in surface snow, total snowpack SWE, and relevant meteorological observations at the end of winter (Figure 7) indicate that enhanced BC concentrations are not primarily due to water loss or dry deposition in the depleting $\mathrm{NH}$ snowpack. While surface BC concentrations are not at seasonal maximum in this final month of winter, they are higher than the seasonal median (Table 2) and appear to be trending upward at times. In contrast, surface $\mathrm{Cl}^{-}$concentrations steadily decrease to the lowest of the season (Figure 7).

Surface BC concentration at BDO increases by over a factor of 4 during the first 3 days of March, while total SWE decreases by 4\% (Figure 7). Even though SWE is decreasing, and from 3 March to 4 March total BC inventory is calculated as decreasing, this increase in surface BC concentration is largely due to a snowfall event with relatively high $B C$ concentration. This snowfall added less $B C$ and SWE than was lost due to melting from 1 day to the next, but the new BC was not immediately flushed. Between 4 March and 5 March, surface BC concentrations increase further. This event could plausibly be due to dry deposition (no snowfall recorded). There was also a slight increase in SWE which may be due to spatial variability, suggesting that part of the apparent BC concentration increase could also be due to spatial heterogeneity. Afterward, surface BC concentration decreases steadily until 8 March but remains constant through the period 8 March to 9 March. Total snowpack BC inventory losses are observed through this interval. A decrease in surface BC concentrations from 10 March to 11 March is likely due to rain, while 11 March to 12 March is marked by a large concentration increase plausibly due to wind redistribution of the surface snow (Figure 7). However, total snowpack BC and SWE are lost between 10 March and 12 March (Figure 7). The rest of the seasons end is marked by sporadic wind, rain, and snow events, all of which likely influence surface BC concentrations. Overall, there are only two $24 \mathrm{~h}$ periods (15 March to 16 March; 23 March to 24 March) where SWE decreases (indicating snowpack melt or sublimation) and surface BC concentrations increase without confounding meteorological factors.

Doherty et al. [2013] describe a melt amplification of BC on the surface snow at Dye 2, Greenland due to inefficient meltwater scavenging. Our observations of $\mathrm{BC}$ behavior during melt in $\mathrm{NH}$ and subsequent hypotheses suggest that $B C$ transported to central Greenland should be more hydrophilic, thus scavenged more efficiently. The Dye 2 snowpack experiences much colder temperatures than the NH snowpack and is over $2000 \mathrm{~m}$ higher above sea level than sites in this study. Consequently, Dye 2 accumulates much drier and colder snow, which likely leads to smaller individual snow grains and pore spaces as well as a slower rate 
of metamorphism. At Dye 2 the average density from the surface down to $60 \mathrm{~cm}$ depth was $0.42 \mathrm{~g} / \mathrm{cm}^{3}$ [Doherty et al., 2013]. The density of individual snow samples in $\mathrm{NH}$ rarely exceeds $0.40 \mathrm{~g} / \mathrm{cm}^{3}$, and the few samples as dense are typically aged and located near the bottom of the snowpack. Densities of the surface layers during the first March melt hover around $0.20 \mathrm{~g} / \mathrm{cm}^{3}$; the median densities in $\mathrm{NH}$ do not exceed $0.27 \mathrm{~g} / \mathrm{cm}^{3}$ (Table 3). Colbeck [1979] describe a numerical model where meltwater percolation rate is inversely related to density and positively related to grain size, which may be factors leading to a mechanical restriction of larger insoluble particles, inhibiting transport by percolating meltwater. High-latitude snowpacks also generally melt much slower than lower latitude snowpacks [Qian et al., 2014] which suggests that melt amplification may be dependent on the magnitude of snowpack melt.

\section{Conclusions}

This study provides extensive measurements of $\mathrm{BC}$ in the melting $\mathrm{NH}$ snowpack. We observe both similarities and differences between dynamics of major ions and BC during times of active melt. In the first 10-40\% of SWE loss, $\mathrm{Cl}^{-}, \mathrm{NO}_{3}{ }^{-}$, and $\mathrm{BC}$ are all lost from the snowpack at a quicker rate than SWE (Figure 3). The $\mathrm{NH}$ snowpack loses a maximum of $84 \%$ nitrate in $51 \%$ SWE loss, $95 \%$ chloride in $34 \%$ SWE loss, and $62 \%$ BC in $24 \%$ SWE loss (Table 5). The rapid loss of ions has been observed in many previous studies; our key finding is that $\mathrm{BC}$ is also efficiently scavenged by meltwater in the NH snowpack. Perhaps this result should have been expected, as the magnitude and rate of $B C$ loss we observed was similar to results found when high concentrations of submicron soot were artificially added to the surface of an actively melting snowpack [Conway et al., 1996].

Black carbon pulses from the New Hampshire snowpack in the same manner as major ions, with the highest meltwater concentrations calculated 1 to 7 days after the start of active melt (Figures 4 and 6). The affinity of $\mathrm{BC}$ for meltwater is likely due to functionalized BC surfaces or small particle diameter. Because calculated dust concentrations are low and size distribution analysis reveals no significant change in $B C$ size during melt, functionalized $B C$ surfaces may play a larger role than $B C$ or particle size in the $B C$ melt dynamics observed in this study. Surface BC concentration analysis at the end of the winter season suggests that local meteorological factors and rate of snowpack melt play important roles in $\mathrm{NH}$ surface $\mathrm{BC}$ concentrations at the end of the winter season.

\section{Acknowledgments}

We would like to thank assistants Cecilia Robinson, Beth Bloom, Andrea Price, Brian Taetzch, Megan Dalton, Tristan Amaral, Louis Saviano, Jeferson Prado Swerts, and Jessica Lindes Fonseca for their help in the lab and field, and Taylor Hodgdon and Amanda Houts for general help with figure formatting. This work was supported by the New Hampshire EPSCoR Program and funding was provided by the National Science Foundation's Research Infrastructure Improvement Award EPS 1101-245. This material is based upon work supported by the National Science Foundation Graduate Research Fellowship under grant 2014186404. Data collected throughout the $\mathrm{NH}$ EPSCoR Track 1 project, including data leading to relevant conclusions in this work, can be found on the Data Discovery Center at https://ddc.unh. edu/ddc_data/variables/list/ under Intensive Snow Measurements. Thanks to all reviewers for helpful criticisms and insight on an earlier draft of this manuscript.

\section{References}

Aamaas, B., C. E. Bøggild, F. Stordal, T. Berntsen, K. Holmen, and J. Ström (2011), Elemental carbon deposition to Svalbard snow from Norwegian settlements and long-range transport, Tellus B, 63, 340-351, doi:10.1111/j.1600-0889.2011.00531.x.

Adolph, A., M. R. Albert, J. Lazarcik, J. E. Dibb, J. M. Amante, and A. Price (2016), Dominance of grain size impacts on seasonal snow albedo at deforested sites in New Hampshire, J. Geophys. Res. Atmos., 121, doi:10.1002/2016JD025362.

Bales, R., R. Davis, and D. Stanley (1989), Ion elution through shallow homogeneous snow, Water Resour. Res., 25, 1869-1877, doi:10.1029/ WR025i008p01869.

Bock, J., and H.-W. Jacobi (2010), Development of a mechanism for nitrate photochemistry in snow, J. Phys. Chem. A, 114, 1790-1796, doi:10.1021/jp909205e.

Bond, T. C., et al. (2013), Bounding the role of black carbon in the climate system: A scientific assessment, J. Geophys. Res. Atmos., 118, 5380-5552, doi:10.1002/jgrd.50171.

Colbeck, S. C. (1981), A simulation of the enrichment of atmospheric pollutants in snow cover runoff, Water Resour. Res., 17, 1383-1388, doi:10.1029/WR017i005p01383.

Colbeck, S. C. (1979), Water flow through heterogeneous snow, Cold Reg. Sci. Technol., 1, 37-45, doi:10.1016/0165-232X(79)90017-X.

Conway, H., A. Gades, and C. F. Raymond (1996), Albedo of dirty snow during conditions of melt, Water Resour. Res., 32, 1713-1718, doi:10.1029/96WR00712.

Dibb, J. E., S. I. Whitlow, and M. Arsenault (2007), Seasonal variations in the soluble ion content of snow at Summit. Greenland: Constraints from three years of daily surface snow samples, Atmos. Environ., 41(24), 5007-5019, doi:10.1016/j.atmosenv.2006.12.010.

Dibb, J. E., and J.-L. Jaffrezo (1997), Air-snow exchange investigations at Summit, Greenland: An overview, J. Geophys. Res., 102, 26,795-26,807, doi:10.1029/96JC02303.

Doherty, S. J., D. A. Hegg, J. E. Johnson, P. K. Quinn, J. P. Schwarz, C. Dang, and S. G. Warren (2016), Causes of variability in light absorption by particles in snow at sites in Idaho and Utah, J. Geophys. Res. Atmos., 121, 4751-4768, doi:10.1002/2015JD024375.

Doherty, S. J., C. Dang, D. A. Hegg, R. Zhang, and S. G. Warren (2014), Black carbon and other light absorbing particles in snow of central North America, J Geophys. Res. Atmos., 119, 12,807-12,831, doi:10.1002/2014JD022350.

Doherty, S. J., T. C. Grenfell, S. Forsström, D. L. Hegg, R. E. Brandt, and S. G. Warren (2013), Observed vertical redistribution of black carbon and other insoluble light-absorbing particles in melting snow, J. Geophys. Res. Atmos., 118, 5553-5569, doi:10.1002/jgrd.50235.

Doherty, S. J., S. G. Warren, T. C. Grenfell, A. D. Clarke, and R. E. Brandt (2010), Light-absorbing impurities in Arctic snow, Atmos. Chem. Phys., 10, 11,647-11,680, doi:10.5194/acp-10-11647-2010.

Feng, X., J. W. Kirchner, C. E. Renshaw, R. S. Osterhuber, B. Klaue, and S. Taylor (2001), A study of solute transport mechanisms using rare earth element tracers and artificial rainstorms on snow, Water Resour. Res., 37, 1425-1435, doi:10.1029/2000WR900376. 
Finamore, A. (2013), It's Cold Outside: Winter Heating in New Hampshire, New Hampshire Employment Security, Economic and Labor Market Information Bureau, New Hampshire, USA.

Flanner, M. G., C. S. Zender, J. T. Randerson, and P. J. Rasch (2007), Present-day climate forcing and response from black carbon in snow, J. Geophys. Res., 112 D11202, doi:10.1029/2006JD008003.

Gustafsson, M. E. R., and L. G. Franzén (1999), Inland transport of marine aerosols in southern Sweden, Atmos. Environ., 34, 313-325, doi:10.1016/S1352-2310(99)00198-3.

Hadley, O. L., C. E. Corrigan, T. W. Kirchstetter, S. S. Cliff, and V. Ramanathan (2010), Measured black carbon deposition on the Sierra Nevada snow pack and implication for snow pack retreat, Atmos. Chem. Phys., 10, 7505-7513, doi:10.5194/acp-10-7505-2010.

Hansen, J., and L. Nazarenko (2004), Soot climate forcing via snow and ice albedos, Proc. Natl. Acad. Sci. U.S.A., 101(2), 423-428, doi:10.1073/ pnas. 2237157100

Harrington, R., and R. C. Bales (1998a), Modeling ionic solute transport in melting snow, Water Resour. Res., 34, 1727-1736, doi:10.1029/ 98WR00557.

Harrington, R., and R. C. Bales (1998b), Interannual, seasonal, and spatial patterns of meltwater and solute fluxes in a seasonal snowpack, Water Resour. Res., 34, 823-831, doi:10.1029/97WR03469.

Hart, V. J. (1997), Spatial variability of soluble ions in surface and preserved snow at Summit, Greenland, M.S. thesis, Dep. of Earth Sciences, Univ. of New Hampshire, Durham, NH, USA.

Hibberd, S. (1984), A model for pollutant concentrations during snow-melt, J. Glaciol., 30(104), 58-65.

Johannessen, M., and A. Henriksen (1978), Chemistry of snow meltwater: Changes in concentration during melting, Water Resour. Res., 14, 615-619, doi:10.1029/WR014i004p00615.

Johannessen, M., T. Dale, and E. Gjessing (1976), Acid precipitation in Norway: The regional distribution of contaminants in snow and the chemical concentration processes during snowmelt, Int. Assoc. Hydrol. Sci., 11(118), 116-120.

Kaspari, S. D., M. Schwikowski, M. Gysel, M. G. Flanner, K. Shichang, S. Hou, and P. A. Mayewski (2011), Recent increase in black carbon concentrations from a Mt. Everest ice core spanning 1860-2000 AD, Geophys. Res. Lett., 38 L04703, doi:10.1029/2010GL046096.

Kuhn, M. (2001), The nutrient cycle through snow and ice, a review, Aquat. Sci., 63(2), 150-167, doi:10.1007/PL00001348.

Laborde, M., P. Mertes, P. Zieger, J. Dommen, U. Baltensperger, and M. Gysel (2012), Sensitivity of the single particle soot photometer to different black carbon types, Atmos. Meas. Tech., 5, 1031-1043, doi:10.5194/amt-5-1031-2012.

Lee, J., V. E. Nez, X. Feng, J. W. Kirchner, R. Osterhuber, and C. E. Renshaw (2008), A study of solute redistribution and transport in seasonal snowpack using natural and artificial tracers, J. Hydrol.., 357(3-4), 243-254, doi:10.1016/j.jhydrol.2008.05.004.

Liang, T., M. Chamecki, and X. Yu (2016), Sea salt aerosol deposition in the coastal zone: A large eddy simulation study, Atmos. Res., 180, 119-127, doi:10.1016/j.atmosres.2016.05.019.

Lundmark, A., and B. Olofsson (2007), Chloride deposition and distribution in soils along a deiced highway-Assessment using different methods of measurement, Water Air Soil Pollut., 182(1-4), 173-185, doi:10.1007/s11270-006-9330-8.

Meinander, O., et al. (2013), Spectral albedo of seasonal snow during intensive melt period at Sodankylä, beyond the Arctic Circle, Atmos. Chem. Phys., 13, 3793-3810, doi:10.5194/acp-13-3793-2013.

Myhre, G., et al. (2013), in Athropogenic and Natural Radiative Forcing, Climate Change 2013: The Physical Science Basis, Contribution of Working Group I to the Fifth Assessment Report of the Intergovernmental Panel on Climate Change, edited by T. F. Stocker et al., Cambridge Univ. Press, Cambridge, U. K., and New York.

Ogren, J. A., R. J. Charlson, and P. J. Groblicki (1983), Determination of elemental carbon in rainwater, Anal. Chem., 55, 1569-1572, doi:10.1021/ac00260a027.

Ohata, S., N. Moteki, J. Schwarz, D. Fahey, and Y. Kondo (2013), Evaluation of a method to measure black carbon particles suspended in rainwater and snow samples, Aerosol Sci. Technol., 47, 1073-1082, doi:10.1080/02786826.2013.824067.

Oliver, B., J. B. Milne, and N. LaBarre (1974), Chloride and lead in urban snow, Water Pollut. Control Fed., 46(4), 766-771.

Polashenski, C. M., J. E. Dibb, M. G. Flanner, J. Y. Chen, Z. R. Courville, A. M. Lai, J. J. Schauer, M. M. Shafer, and M. Bergin (2015), Neither dust nor black carbon causing apparent albedo decline in Greenland's dry snow zone: Implications for MODIS C5 surface reflectance, Geophys. Res. Lett., 42, 9319-9327, doi:10.1002/2015GL065912.

Qian, Y., H. Wang, R. Zhang, M. G. Flanner, and P. J. Rasch (2014), A sensitivity study on modeling black carbon in snow and its radiative forcing over the Arctic and Northern China, Environ. Res. Lett, 9, doi:10.1088/1748-9326/9/6/064001.

Satoh, F., M. Nomura, H. Masumoto, D. Ashiya, and K. Sasa (1999), lonic elution from the acidic snowpack during spring thaw period in the northern part of Hokkaido, Res. Bull. Hokkaido Univ. For., 56(2), 1-10.

Schwarz, J. P., R. S. Gao, A. E. Perring, J. R. Spackman, and D. W. Fahey (2013), Black carbon aerosol size in snow, Sci. Rep., 3, 1356, doi:10.1038/ srep01356.

Schwarz, J. P., S. J. Doherty, F. Li, S. T. Ruggiero, C. E. Tanner, A. E. Perring, R. S. Gao, and D. W. Fahey (2012), Assessing single particle soot photometer and integrating sphere/integrating sandwich spectrophotometer measurement techniques for quantifying black carbon concentration in snow, Atmos. Meas. Tech., 5, 2581-2592, doi:10.5194/amt-5-2581-2012.

Schwarz, J. P., et al. (2006), Single-particle measurements of mid-latitude black carbon and light-scattering aerosols from the boundary layer to the lower stratosphere, J. Geophys. Res., 111 D16207, 1-15, doi:10.1029/2006JD007076.

Sergides, C. A., J. A. Jassim, A. R. Chughtai, and D. M. Smith (1987), The structure of hexane soot. Part III: Ozonation studies, Appl. Spectrosc., 41(3), 248-258, doi:10.1366/000370287448805

Sterle, K. M., J. R. McConnell, J. Dozier, R. Edwards, and M. G. Flanner (2013), Retention and radiative forcing of black carbon in eastern Sierra Nevada snow, Cryosphere, 7, 365-374, doi:10.5194/tc-7-365-2013.

Svensson, J., J. Ström, M. Hansson, H. Lihavainen, and V.-M. Kerminen (2013), Observed metre scale horizontal variability of elemental carbon in surface snow, Environ. Res. Lett., 8, 3034012, doi:10.1088/1748-9326/8/3/034012.

Tedesco, M., S. Doherty, X. Fettweis, P. Alexander, J. Jeyaratnam, and J. Stroeve (2016), The darkening of the Greenland ice sheet: Trends, drivers, and projections (1981-2100), Cryosphere, 10, 477-496, doi:10.5194/tc-10-477-2016.

Tukey, J. (1977), Exploratory Data Analysis, pp. 43-44, Addison-Wesley, Boston, Massachusetts.

Ulrich, J. (2015), TTR: Technical trading rules, R package version 0.23-0, CRAN.R-TTR.

U.S. EPA (2009), Final report: Integrated science assessment for particulate matter, U.S. Environmental Protection Agency, Washington, D. C., EPA/600/R-08/139 F.

Williams, M. W., C. Seibold, and K. Chowanski (2009), Storage and release of solutes from a subalpine seasonal snowpack: Soil and stream water response, Niwot Ridge, Colorado, Biogeochemistry, 95(1), 77-94, doi:10.1007/s10533-009-9288-x.

Williams, M. W., and J. M. Melack (1991), Solute chemistry of snowmelt and runoff in an Alpine Basin, Sierra Nevada, Water Resour. Res., 27, 1575-1588, doi:10.1029/90WR02774. 
Wendl, I. A., J. A. Menking, R. Färber, M. Gysel, S. D. Kaspari, M. J. G. Laborde, and M. Schwikowski (2014), Optimized method for black carbon analysis in ice and snow using the single particle soot photometer, Atmos. Meas. Tech., 7, 2667-2681, doi:10.5194/amt-7-2667-2014.

Xu, B., J. Cao, D. R. Joswiak, X. Liu, H. Zhao, and J. He (2012), Post-depositional enrichment of black soot in snow-pack and accelerated melting of Tibetan glaciers, Environ. Res. Lett., 7, doi:10.1088/1748-9326/7/1/014022. 